\title{
Homing Ability of Japanese Chum Salmon and Differences in their Return Timing by Reproductive Season
}

\author{
Masaya Iida \\ Japan Sea National Fisheries Research Institute, Japan Fisheries Research and Education Agency, Chuou-ku, \\ Niigata 951-8121, Japan
}

Keywords: chum salmon, homing, natal tributary, otolith thermal marking, straying

To increase their harvest, the juveniles of chum salmon are stocked in several tributaries of river systems, and homing adults are captured from each tributary for hatchery broodstock. Therefore, it is important to understand the homing behavior of chum salmon for a successful management of their resources. In this study, I surveyed the homing ability of chum salmon and differences in their return timing by reproductive season.

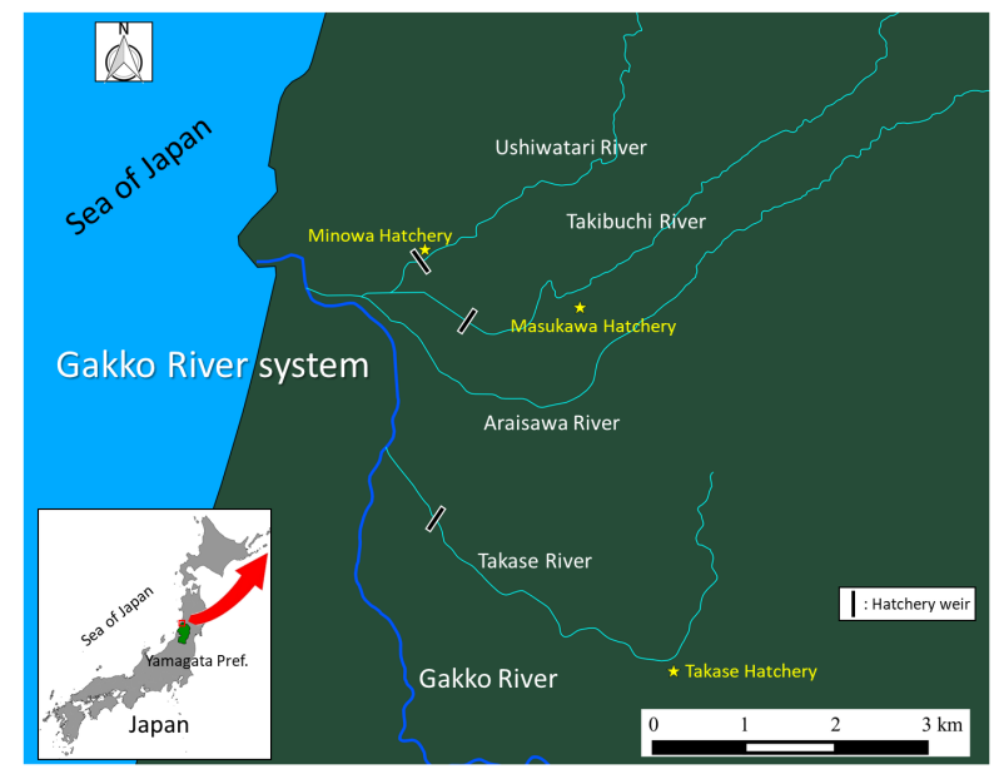

Fig. 1. Map of the Gakko River system, Yamagata Prefecture, Japan. Yellow stars and black rectangles indicate the hatcheries and weirs from where chum salmon adults were collected for hatchery brood stocks. Note that the confluence of the Araisawa River with the Gakko River is only $2.3 \mathrm{~km}$ from that of the Takase River.

The study was conducted in the Gakko River system, Yamagata Prefecture, Japan. There are three hatcheries in the Gakko River system, the Minowa hatchery on the Ushiwatari River, Masukawa hatchery on the Takibuchi River, and Takase hatchery on the Takase River (Fig. 1). Seven groups of chum salmon juveniles with unique otolith-thermal-marking depending on their natal tributary (hatchery) and date of reproduction were released through each hatchery discharge channel in 2009-2011 (Iida et al. in press). The number and mean body weight of chum salmon of the seven groups ranged from 82 thousand to 1.8 million and 1.0 to $1.7 \mathrm{~g}$, respectively. The returning adults were captured each year between October and January at weirs of each of the three tributaries (Fig. 1). One hundred adults ( 50 males and 50 females) were sampled every ten days; their age was determined by analyzing their scales, and the otoliths were checked to identify the origin of the specimens in 2011-2015. Referring to Morita et al. (2015), the number of escapements of the groups in each tributary $\left(E_{g, r}\right)$ was estimated as:

$$
E_{g, r}=\sum_{i} \sum_{j} p_{M, g, r, i, j} \cdot y_{M, g, r, i, j}+\sum_{i} \sum_{j} p_{F, g, r, i, j} \cdot y_{F, g, r, i, j}
$$

where, $p_{M, g, r, i, j}$ and $p_{F, g, r, i, j}$ are the proportion of the otolith-marked male and female fish $(g)$ at age $i$ and season $j$ in a tributary $(r)$, respectively; and $y_{M, g, r, i, j}$ and $y_{F, g, r, i, j}$ are the number of male and female fish caught in the tributary $(r)$ at season $j$ when the marked fish returned at age $i$. 
The median (range) proportion of the group that returned to their natal tributary (i.e., number of escapement to the natal tributary/total number of escapement to the three tributaries) was $86.3 \%(49.2 \%-100 \%, n=7)$. The results suggest that chum salmon can detect their natal tributary from adjacent non-natal first-order tributaries, and they often stray into second-order tributaries. The peak escapement of the groups was observed during their reproductive season, or just before and after the season of their reproduction. The median (range) proportion of the number of escapements of the groups returning during reproductive season and ten days before and after the reproductive season to the total number of escapements of the group was $84.1 \%(79.1 \%-88.9 \%, n=7)$. These results suggest that chum salmon can detect their natal tributary, and they return to their natal river during every reproductive event.

\section{REFERENCES}

Iida, M., M. Ban, D. Noguchi, Y. Miyauchi, and S., Katayama. 2018. Comparison of return rates of chum salmon Oncorhynchus keta released at various times into the Gakko River, Yamagata Prefecture, Japan. Aqua. Sci. 66: 137-140. (In Japanese with English abstract)

Morita, K., N. Ayumi, and M. Kikuchi. 2015. River temperature drives salmon survivorship: is it determined prior to ocean entry? R. Soc. Open Sci. 2: 140312. 